\title{
Paleomagnetic Biases Inferred from Numerical Dynamos and the Search for Geodynamo Evolution
}

\author{
Peter E. Driscoll ${ }^{1, *}$ \\ ${ }^{1}$ Carnegie Institution for Science, Department of Terrestrial Magnetism, Washington, \\ D.C., USA
}

Correspondence*:

Corresponding Author

pdriscoll@ciw.edu

\section{ABSTRACT}

The orientation and intensity of the paleomagnetic field is central to our understanding of the history of the Earth. The paleomagnetic signature of the singular most event, inner core nucleation, however, remains elusive. In this study we study numerical dynamo simulations from a paleomagnetic perspective to explore how long observations must be time-averaged to obtain stable virtual geomagnetic pole (VGP) directions and global field intensities. We find that running averages over $20-40 \mathrm{kyr}$ are needed to obtain stable VGP's with $\alpha_{95}<10^{\circ}$, and over $40-120$ kyr for $\alpha_{95}<5^{\circ}$. We find that models with higher heat flux and more frequent polarity reversals require longer time averages, and that obtaining stable intensities requires longer time averaging than obtaining stable directions. Running averages of local field intensity and inclination produce underestimates of VDM by factors of $0.9-0.6$ and overestimates of VADM by factors of $1-1.2$ as heat flux and reversal frequency increases. We derive a scaling law connecting reversal frequency to paleointensity bias that could be applied to records where reversal frequency is known. Applied to the PINT paleointensity record, these biases produce little change to the overall trend of a relatively flat but scattered intensity over the last $2 \mathrm{Ga}$. A more careful debiasing applied during periods when the reversal frequency is known could reveal previously obscured features in the paleointensity record.

Keywords: geodynamo, paleointensity, Earth evolution

\section{INTRODUCTION}

Our knowledge of the history of Earth's magnetic field derives from paleomagnetic signals preserved in rocks. Many applications of paleomagnetism rely on an assumption that only the global axial dipole (GAD) component remains after averaging the complex time-variable magnetic field over a sufficient amount of time, typically assumed to be around 10-20 kyr (Merrill and McFadden, 2003). This GAD field assumption has been extremely rewarding, for example in obtaining paleointensities (e.g. Biggin et al., 2009; Tauxe and Yamazaki, 2015), paleodirections and tectonic reconstructions (e.g. Torsvik et al., 2012; Raub et al., 2015), and even paleoclimate studies that rely on paleomagnetically derived paleolatitudes (Evans et al. 2000; Williams and Schmidt, 2004). Tests of the GAD field assumption have generally found support for its validity (e.g. Johnson et al., 1995; Acton et al., 1996; Meert et al., 2003; McElhinny, 2004; Evans, 
2006; Swanson-Hysell et al., 2009; Panzik and Evans, 2014; Veikkolainen et al., 2014, 2017; Johnson and McFadden, 2015), although some have proposed long-term deviations from GAD in the Precambrian (Kent and Smethurst, 1998; Abrajevitch and Van der Voo, 2010).

Theoretically a GAD field is predicted over long time averaging because the equations governing dynamo action are symmetric about the transformation $\vec{B} \rightarrow-\vec{B}$, about the equator, and in rotation about the polar axis (Gubbins and Zhang, 1993), implying that when randomly sampled and time averaged long enough only the axial dipole term should retain a non-zero amplitude. However, the length of time required to average out all non-GAD terms remains uncertain, especially during periods when the field is highly variable or frequently reversing (Merrill and McFadden, 2003).

Despite the remarkable success of the GAD assumption, a significant amount of anomalous data that cannot be explained by a simple GAD field remain largely unexplained. In particular, a growing number of anomalous directions in the Neoproterozoic (Maloof et al., 2006; Abrajevitch and Van der Voo, 2010, McCausland et al., 2011; Swanson-Hysell et al., 2012; Klein et al., 2015; Halls et al., 2015; Levashova et al., 2015; Bazhenov et al., 2016) have been variously interpreted as caused by extremely rapid plate motions, significant true polar wander, long-term non-GAD magnetic field components, or some mixture of these.

An additional puzzle that has garnered recent attention is the surprising lack of an obvious paleomagnetic signature of inner core nucleation (ICN) in the paleointensity record. Biggin et al. (2015) proposed that a paleointensity peak observed around $1.2 \mathrm{Ga}$ could be a signature of ICN, but the primary signature of some of the underlying data has been questioned (Smirnov et al., 2016). Simultaneously, recent upward revisions of the thermal conductivity of iron have decreased estimates of the age of the inner core to Neoproterozoic time (e.g. Driscoll and Bercovici, 2014; Davies, 2015; Nimmo, 2015).

There are at least three possible reasons for the lack of a clear paleomagnetic signature of ICN: (1) the paleomagnetic signature of ICN is too small or old to be preserved, (2) the paleointensity record is too sparse, or (3) the signature is obscured by non-GAD fields. Recently, it has been proposed that prior to inner core nucleation around $600 \mathrm{Ma}$ a non-GAD field may have been persistent in the Neoproterozoic as a consequence of the geodynamo being powered only by weak thermal convection at the time (Driscoll, 2016, Landeau et al., 2017). Unfortunately the paleointensity record around this time is sparse, possibly due to a lack of wide spread magmatism, a lack of preservation, inability to recover primary remanence, or low quality criteria. Therefore, from both empirical and theoretical grounds there is an impetus to investigate how paleomagnetic recordings are affected by a range of dynamo behavior and field morphologies. Obtaining new high quality data, developing new analysis techniques of old data, and investigating synthetic data from numerical dynamo models all provide a way forward.

Several previous studies have generated synthetic observations from numerical dynamos for different purposes. Wicht (2005) found the that the observed length of reversal durations can change by an order of magnitude as a function of observed site latitude. A statistical analysis of several numerical dynamos by McMillan et al. (2001) found significant variation in field components when averaged over $100 \mathrm{kyr}$, and that a minimum of 10 dipole decays times were required to obtain stable estimates of the dipole field. Similarly Davies and Constable (2014) found that averaging over several hundred thousand years was required to obtain stable dipole field estimates, and longer averaging is needed for more turbulent (higher $R m$ ) dynamo models. Lhuillier and Gilder (2013) found that roughly one million years was required to achieve stationary intensities and directions, and that these quantities correlate with stable chron duration. 
In this paper we systematically explore how long a time average is required to obtain a GAD field from a range of dynamo regimes that span stable dipolar to reversing non-dipolar. We generate local synthetic (or "virtual") geomagnetic observations from these models to investigate possible intrinsic biases generated by the core magnetic field itself, i.e. not caused by rock magnetic affects, alterations, or external forcings. In particular we aim to identify whether the dynamics of the core can produce predictable biases in the time averaged paleomagnetic field, in terms of both paleomagnetic directions and paleointensities, and whether such biases can be identified and removed from paleomagnetic data to reveal previously obscured features.

In $\$ 2$ we review the paleointensity record, accounting for several recently identified issues with certain paleointensity estimates. In $\$ 3$ we introduce the numerical dynamos and synthetic analysis methods, followed by results in $\$ 4$. Finally, implications and conclusions are in $\$ 5$ and $\$ 6$.

\section{PINT DATABASE}

The PaleoINTensity (PINT) database of Biggin et al. (2009), last updated in 2015, is a compilation of absolute paleointensity measurements using the Thellier method with each site mean produced from at least 3 individual measurements and a standard deviation that is not more than $25 \%$ of the mean. The database (downloaded from http://earth.liv.ac.uk/pint/) contains a total of 4010 dated paleointensity measurements, which is composed of 3248 virtual dipole moments (VDM) and 762 virtual axial dipole moment (VADM). We focus on data over the last $2 \mathrm{Ga}$ in order to investigate the possible signature of ICN, which is thought to have occurred during that time (Driscoll and Bercovici, 2014, Davies, 2015; Nimmo, 2015).

Figure 1 shows virtual dipole moment (VDM) from a subset of the PINT paleointensity database (Biggin et al., 2009) over $0-2 \mathrm{Ga}$. Individual intensity estimates are shown as circles and open circles are data that have been questioned (see below) and are excluded from the smoothing analysis. We apply an inverse distance squared smoothing (Algeo, 1996; Driscoll and Evans, 2016) to the remaining dataset to produce a running mean $\mu(t) \mathrm{V}(\mathrm{A}) \mathrm{DM}$ profile (black line), standard deviation $\sigma(t)$ (dark grey), and standard error $e(t)$ (light grey). The vertical thickness of $\sigma$ indicates the measured variability of V(A)DM over the chosen smoothing time scale of $30 \mathrm{Myr}$.

As mentioned above, several data points have been excluded from the smoothing analysis. As pointed out by Smirnov et al. (2016) low temperature (secondary) or multidomain components will produce steep demagnetization curves (Arai plots) that over estimate the primary intensity. Examples of this effect may include the Keweenawan rocks dated at $1.1 \mathrm{Ga}$, which exhibit anomalously high paleointensities and puzzling asymmetries between the normal and reversed polarity sections (Pesonen and Halls, 1983). Swanson-Hysell et al. (2009) interpret these asymmetries as artifacts caused by changes in paleolatitude. The Keweenawan intensities of Pesonen and Halls (1983) are also 2-3 times higher than the Tudor Gabbros (Yu and Dunlop, 2001), Abitibi dykes (Macouin et al., 2003), and central Arizona diabase sheets (Donadini et al., 2011), all of which were emplaced within about 50 Myr of the Keweenawan. The period of high paleointensity found by Pesonen and Halls (1983) may be a real transient, which is consistent with modern levels of intrinsic geodynamo variability, or if fact may be an artifact (Yu and Dunlop, 2001; Valet, 2003). Similarly, a series of high paleointensity measurements from the Gardar Basalts in southern Greenland (Thomas, 1993; Thomas and Piper, 1995) may have misinterpreted several low temperature multidomain magnetizations as a primary single domain paleointensity. In light of these concerns we exclude these data from the smoothing curve and mark them with open circles in Figure 1 . In all, we exclude 20 points with ages 1087-1105 Ma from Pesonen and Halls (1983), 18 points all with age 1300 Ma from Thomas (1993), and 39 points all with age $1300 \mathrm{Ma}$ from Thomas and Piper (1995). 
The smoothing analysis applied to this reduced dataset produces a roughly flat paleointensity history over the past $2 \mathrm{Ga}$. Variability is highest during the Neoproterozoic where there is a relative sparsity of data. This revision to the paleointensity analysis of Biggin et al. (2015) implies no obvious signature for inner core nucleation. In the following sections we investigate how the dynamo regime, which is predicted to change after ICN, would be reflected in observations. Later in $\$ 5$ we revisit this paleointensity record in light of our findings.

\section{NUMERICAL DYNAMOS AND ANALYSIS METHOD}

We produce a range of dynamo models, from stable dipolar to reversing non-dipolar, to analyze like synthetic paleomagnetic data (i.e. from a point on Earth's surface). Possible biases and correlations between "known" and "observed" quantities will be quantified as a function of the length of time averaging and the dipole stability.

\subsection{Dynamo Model Setup}

The dynamo models are computed using the Rayleigh dynamo code (Featherstone and Hindman, 2016; Matsui et al., 2016). All models share the following control parameters: $E=10^{-3}, \operatorname{Ra}=10^{6}, \operatorname{Pr}=1$, $P m=10$, insulating magnetic boundary conditions, no-slip velocity conditions, inner-outer core radius ratio of 0.35, and fixed temperature gradient at both boundaries (see Table 1). These relatively high Ekman number simulations produce Earth-like large scale magnetic features (see below) and polarity reversals that resemble geomagnetic observations, and are numerically cheap so they can be run extremely long times to produce low frequency statistics. The inner boundary temperature gradient $d T / d r_{i}$, fixed in time in each model, spans a range of $0.8-12$ (in non-dimensional units) that produces stable dipolar dynamos on the lower end to unstable, reversing non-dipolar dynamos at the high end (Table 1). The temperature gradient at the outer boundary is set to balance the heat flow at the base so that energy is conserved and there is no internal sink or source.

Time is scaled from thermal diffusion times (implemented in the code) to years by multiplying by a factor $\tau_{d i p} /\left(P m\left(r_{o} / \pi\right)^{2}\right)$, where $r_{o}=1.5384$ is dimensionless outer core radius and $\tau_{d i p}=50 \mathrm{kyr}$ is the assumed magnetic dipole decay time of the core. We adopt the same definition of a polarity reversal proposed by Driscoll and Olson (2009): that the dipole co-latitude $\theta_{\text {dip }}$ spend at least $20 \mathrm{kyr}$ in a stable polarity before and after a reversal.

\subsection{Analysis Method}

From each model we compute Gauss coefficients over time $g_{l, m}(t)$ and $h_{l, m}(t)$ at Earth's surface from magnetic field spectra at the CMB (e.g. Merrill et al., 1996). Although the dynamo model spectra are resolved out to harmonic degree $l_{\max }=64$ we only compute Gauss coefficients out to $l_{\max }=8$ because larger harmonics contribute very little to the surface magnetic field.

From the Gauss coefficients we compute the rms non-axial dipole (NAD),

$$
g_{N A D}(t)=\left[\sum_{l=1}^{l_{\max }} \sum_{m=0}^{l}\left\{g_{l, m}(t)^{2}+h_{l, m}(t)^{2}\right\}-g_{1,0}(t)^{2}\right]^{1 / 2}
$$


and the rms dipole intensity,

$$
g_{D}(t)=\sqrt{g_{1,0}(t)^{2}+g_{1,1}(t)^{2}+h_{1,1}(t)^{2}}
$$

149 where

$$
\Psi(r, \theta, \phi, t)=a \sum_{l} \sum_{m}\left(\frac{a}{r}\right)^{l+1} P_{l}^{m}(\cos \theta)\left(g_{l, m}(t) \cos m \phi+h_{l, m}(t) \sin m \phi\right)
$$

156 inclination $I$,

$$
I=\tan ^{-1}\left[\frac{Z}{\sqrt{X^{2}+Y^{2}}}\right]
$$

angular pole distribution $\alpha_{95}$ with $95 \%$ probability,

$$
\alpha_{95}=\cos ^{-1}\left[1-\frac{N-R}{R}\left\{\left(\frac{1}{0.05}\right)^{\frac{1}{N-1}}-1\right\}\right]
$$

158 and Fisher's precision parameter $k$

$$
k=\frac{N-1}{N-R}
$$

159 where

$$
R=\left[\left(\sum l_{i}\right)^{2}+\left(\sum m_{i}\right)^{2}+\left(\sum n_{i}\right)^{2}\right]^{1 / 2}
$$

and the directional cosines are $l_{i}=\cos D_{i} \cos I_{i}, m_{i}=\sin D_{i} \cos I_{i}$, and $n_{i}=\sin I_{i}$ (Merrill et al., 1996).

The (dimensionless) global dipole moment $p_{D M}$ is

$$
p_{D M}=4 \pi a^{3} g_{D}
$$


162 163 164 165 166

167

168 169 170 171 172 173 174 175 176

where $a=2.8157$ is the dimensionless radius of Earth (Merrill et al., 1996). The global axial dipole moment $p_{A D M}$ is the same as in (11) but with only the $g_{1,0}$ term in (2). These global dipole moments $p_{D M}$ and $p_{A D M}$ can be considered as the "true" values and will be compared to synthetic or "virtual" observations of these quantities. The "virtual" dipole moment (VDM) is computed from the local magnetic intensity $F$ by (Merrill et al., 1996)

$$
p_{V D M}=\frac{4 \pi a^{3}}{2} F\left(1+3 \cos ^{2} I\right)^{1 / 2}
$$

and similarly for the "virtual" axial dipole moment (VADM)

$$
p_{V A D M}=4 \pi a^{3} F\left(1+3 \cos ^{2} \theta\right)^{-1 / 2}
$$

which reduces to $p_{V A D M}=4 \pi a^{3} F$ at the equator $(\theta=\pi / 2)$.

We also consider the role of time averaging in producing a paleomagnetic direction or intensity. The length of the time average $\tau$ applied to the dynamo model time series could be interpreted as the time over which a series of paleomagnetic observations are averaged to get a single data point in time (e.g. segment of a sedimentary sequence), or the time over which the magnetic carrier obtains a remnant signal of the ambient field (e.g. cooling of a magmatic unit below its Curie temperature). We average each quantity of interest over a number of smoothing times $\tau$ from 5 to $500 \mathrm{kyr}$. For each $\tau$ the dynamo model time series is chopped into $N=\Delta t / \tau$ sub series, where $\Delta t$ is the total length of the model in kyr. Within each sub-series a running mean is computed following the method of Davies and Constable (2014):

$$
\overline{x\left(t_{i}\right)}=\overline{x\left(t_{i-1}\right)} \frac{(i-1)}{i}+\frac{1}{i} x\left(t_{i}\right)
$$

177 where $x(t)$ is some output from the dynamo model and $t_{i}$ is time at the $i^{t h}$ sampling index within each

\section{RESULTS} sub-series. The running average is computed up to $t_{i}=\tau$ for each sub series, and then an average of the running averages is computed. Dynamo model output quantities have an output sampling frequency of about once every 1 kyr for all models.

We apply the analysis methods described above to the suite of dynamo simulations to investigate how long a time base-line of observations must be averaged to obtain a pure global axial dipole (GAD) field, and how this time baseline depends on the dynamics of the model. Finally we investigate how local virtual observations of intensity compare to the true global values for the suite of dynamos.

\subsection{An Earth-like Dynamo Model}

To demonstrate that these models are in a relevant region of parameter space, we first focus the details of an "Earth-like" model with $d T / d r_{i}=4$, which we will refer to as "model 4". Figure 2 shows the time series of dipole co-latitude and the axial dipole Gauss coefficient $g_{l=1, m=0}$ for model 4. This model reverses 20 times over 7.6 Myr (2.61 reversals per Myr) and the dipole spends about equal time in each hemisphere. It is "Earth-like" according to the definition of Christensen et al. (2009) with an axial to non-axial dipole ratio "AD/NAD" of 0.29 , an odd to even ratio "O/E" of 0.87 , and zonal to non-zonal ratio "Z/NZ" of 0.05 , all similar to the Earth-like values of $1.4,1.0$, and 0.15 respectively. Using the standard deviations expected by Christensen et al. (2009), these values produce a summary rating of $\chi^{2}=6.21$. 
These magnetic field statistics give us some confidence that our models produce magnetic fields that are generally "Earth-like" at the largest scales even though they are many orders of magnitude from the Earth in several non-dimensional parameters. A recent comparison of "Earth-like" dynamos that span a huge range in control parameters demonstrates that the large scale features and low frequency variability can be captured even when the small scale dynamics are not resolved (Aubert et al., 2017). Nevertheless, our results should be compared to higher resolution simulations in the future.

Also shown in Figure 2 are time series of magnetic inclination and declination as observed at an arbitrary point on Earth's surface: at the equator $\theta=\pi / 2$ and $\phi=0$. Synthetic observations generated at this point will be analyzed from a paleomagnetic perspective and compared to the true solution. Next we will test the ability to retrieve the true global magnetic directions and intensities from a time series of synthetic paleomagnetic observations.

\subsection{Effects of Time Averaging}

Figure 3 shows an example of the time series smoothing analysis in (14) applied to $g_{1,0}$ from model 4 for four smoothing lengths $\tau$. Clearly in this occasionally reversing model $g_{1,0}$ has long-term variability on Myr time scales that is not captured by smoothing over $500 \mathrm{kyr}$. However, rms quantities may converge to stationary values faster.

Figure 4 shows the mean and standard deviation of the running mean of four output quantities (i.e. $\overline{x(\tau)}$ ) from model 4 for a range of $\tau$. Figure 4 a shows that the average of $\overline{g_{1,0}(\tau)}$ (i.e. the average of the running averages from all sub series) converges to zero for all $\tau$, as expected for this reversing model that spends roughly equal time in normal and reversed polarity states (Figure 2). The relatively large standard deviation of $\overline{g_{1,0}(\tau)}$ reflects the long-term variability that is not averaged out within each sub series. Figure $4 \mathrm{~b}$ shows that the average rms non-axial dipole field (GNAD) from (1) is also near zero for all $\tau$, implying that all other field harmonics (other than $g_{1,0}$ ) individually balance to zero. The standard deviation of GNAD also approaches zero at large $\tau$, implying that non-axial dipole fields more consistently balance out over longer time averaging than $g_{1,0}$. Figure $4 c$ shows that the running mean of rms dipole from (2) and axial dipole coefficients are stationary and non-zero over all $\tau$. Figure $4 \mathrm{~d}$ shows that the local magnetic amplitude $F_{e q}$ at the equator is similarly stationary and non-zero over all $\tau$ and similar in amplitude to the rms axial dipole. A more detailed comparison between observed and true intensities is below.

Figure 5 shows the average of running means of four local magnetic pole-related quantities from model 4: declination $D_{e q}$ from (6), inclination $I_{e q}$ from (7), $\alpha_{95}$ from (8), and Fisher's precision parameter $k$ from (9). The average of the running mean inclination and declination hover around zero, which is the expected orientation of an axial dipole observed at the equator. The standard deviation of the running mean inclination and declination decrease steadily with $\tau$ as the non-axial magnetic terms average out, similar to the trend in GNAD in Figure $4 \mathrm{~b}$. The angular spread $\alpha_{95}$ in the virtual geomagnetic pole (VGP) decreases rapidly with $\tau$ while the precision parameter $k$ plateaus around 15. A vertical dashed line is drawn at the largest $\tau$ where $\alpha_{95}<10^{\circ}$, which is a typical threshold value for computing a VGP (e.g. Van der Voo 1990). For model 4 this occurs at $\tau=30 \mathrm{kyr}$, implying that to obtain a stable VGP orientation the local field must be averaged over at least about $30 \mathrm{kyr}$.

\subsection{Dynamo regimes}

Next we investigate how the dynamical regime of the dynamo influences synthetic observations at the surface and how they differ (if at all) from the known solutions. The suite of dynamos span regimes from stable non-reversing at low heat flux $\left(d T / d r_{i}=1\right)$ to reversing non-dipolar at high heat flux $\left(d T / d r_{i}=12\right)$. 
The major dynamo transition from dipolar non-reversing models to non-dipolar reversing models occurs around $d T / d r_{i}=3$. This transition is apparent in Figure 6a where volume averaged magnetic energy (ME) drops below kinetic energy (KE) due to a weakening of the axial dipole, Figure $6 \mathrm{~b}$ where rms $g_{1,0}$ drops by a factor of $\sim 4$, Figure $6 \mathrm{c}$ where reversals begin, and Figure $6 \mathrm{~d}$ where the axial dipolarity $\left(g_{1,0} / g_{r m s}\right)$ drops below $\sim 0.5$.

Interestingly, Figure 6a shows that volume averaged ME drops to a minimum at the onset of reversals $\left(d T / d r_{i}=3\right)$ and then increases with heat flux in parallel with KE as more energy is pumped into the domain. Because of the preference for low harmonic degree fields at the surface, the decrease in the dipole dominates the total surface magnetic field, leading to a sudden drop in $g_{1,0}$ at the reversing onset and a floor of $g_{1,0}=0.05$ for more energetic models. This $g_{1,0}$ floor may indicate saturation of the dipole field where generation of a stronger dipole by faster convective velocities is balanced by turbulent disruption of the large scale flow. Dipole reversal frequency increases with bottom heat flux (Figure 6c), implying that $d T / d r_{i}$ is a proxy for reversal frequency or dipole stability in these models. The plateau in reversal frequency around $8 / \mathrm{Myr}$ is an artifact of our requirement that a reversal be bracketed by stable periods longer than $20 \mathrm{kyr}$, which become less common as the heat flux increases.

\subsection{Obtaining stable poles and intensities from synthetic observations}

Next we apply the local paleomagnetic analysis methods from $\$ 3.2$ to all models with the goal of quantifying how the time required to obtain a stable paleomagnetic pole and intensity depends on the dynamical state of the core. We define the critical smoothing time $\tau_{\text {crit }}$ as the running mean length where $\alpha_{95}$ falls below a threshold value of either $5^{\circ}$ or $10^{\circ}$. This is the length of time averaging needed to obtain a stable virtual geomagnetic pole (VGP) position from continuous observations at a single location.

Figure $7 \mathrm{a}$ shows that the critical smoothing time $\tau_{\text {crit }}$ increases for more energetic dynamos driven by larger bottom heat fluxes. A threshold of $\alpha_{95}<10^{\circ}$ requires $\tau_{c r i t}$ of 20-40 kyr, while a threshold of $\alpha_{95}<5^{\circ}$ requires $\tau_{c r i t}$ of $40-150 \mathrm{kyr}$. Figures $7 \mathrm{~b}$-d show the average running mean of several other dynamo statistics computed at $\tau_{c r i t}$. Surprisingly Figure $7 \mathrm{~d}$ shows that $g_{N A D}\left(\tau_{c r i t}\right)$ does not converge to zero for stable dipolar models $\left(d T / d r_{i}<4\right)$, which implies that directional VGP scatter converges faster in a running average than the intensity of the non-dipolar magnetic field. More generally, this implies that longer running averages are needed to converge to stationary intensities than directions.

Next we analyze synthetic dipole moment observations at a point on the equator. Running averages of the true and virtual dipole moments defined in $(11,12,13)$ are compared in Figure 8 for a single smoothing time of $\tau=50$ kyr. Figures $8 \mathrm{a}$ and $\mathrm{b}$ show a factor of $\sim 5$ drop in dipole moment in going from non-reversing to reversing models as seen in Figure 6 a.

Bias in intensity observations can be investigated by comparing the ratio of observed dipole moment $p_{V D M}$ in $(12)$ to true dipole moment $p_{D M}$ in 111 ,

$$
B_{V D M}=\frac{p_{V D M}}{p_{D M}}=\frac{1}{2} \frac{F\left(1+3 \cos ^{2} I\right)^{1 / 2}}{g_{D}}
$$

270 and similarly for the ratio of observed axial dipole moment $p_{V A D M}$ in (13) to true axial dipole moment $271 p_{A D M}$,

$$
B_{V A D M}=\frac{p_{V A D M}}{p_{A D M}}=\frac{F}{\sqrt{g_{1,0}^{2}}}
$$




\section{IMPLICATIONS} time averaging. slightly more than $\sqrt{g_{1,0}^{2}}$.

where $F$ and $I$ are derived from local observations at the equator. Figure $8 \mathrm{c}$ (and Table 1 ) shows that VDM is systematically low compared to true DM by a factor of $\sim 0.9$ for non-reversing dipolar models, and trends down to a factor of $\sim 0.6$ for reversing models. The drop in Figure $8 \mathrm{c}$ is caused mainly by a drop in $F / g_{D}$ because the running average inclination at $\tau=50 \mathrm{kyr}$ is less than $2^{\circ}$ for all models (Figure $5 \mathrm{~b}$ ). The decrease in $F / g_{D}$ is caused by the local intensity $F$ becoming more and more contaminated by non-dipole field components with arbitrary sign as heat flux increases, so that on average $F<g_{D}$. Figure 8 ; shows this ratio is the same for $\tau=50 \mathrm{kyr}, 100 \mathrm{kyr}$, and $500 \mathrm{kyr}$, indicating that this bias lingers even with longer

On the contrary we find an increasing trend in the ratio of VADM/ADM from 1 to $\sim 1.2$, which is caused by $\sqrt{g_{1,0}^{2}}$ decreasing faster than $F$ with increasing heat flux. This bias can be attributed to the GAD assumption that the field is purely axial when it is not and non-axial dipolar field components contributing to increase $F$. This trend implies that VADM systematically overestimates the true DM for reversing dynamos. Combining $F<g_{D}$ from Figure $8 f$ and $F>\sqrt{g_{1,0}^{2}}$ from Figure $8 d$ gives

$$
\sqrt{g_{1,0}^{2}}<F<\sqrt{g_{1,0}^{2}+g_{1,1}^{2}+h_{1,1}^{2}}
$$

implying that local fields of opposite sign combine to decrease $F$ slightly less than $g_{D}$ but to increase it

Lastly, we recast these results from a function of bottom heat flow to a function of reversal frequency per Myr $f_{r}$ in Figure 9. We find a similar inverse relationship between $k$ and $f_{r}$ as Lhuillier and Gilder (2013) in Figure $9 \mathrm{~b}$. The paleointensity bias found in Figure 8 could be applied to paleomagnetic observations if the reversal frequency is independently known. With this in mind we fit linear functions to the VDM and VADM data (Figures $8 \mathrm{c}$ and $\mathrm{d}$ ) as,

$$
\frac{p_{V(A) D M}}{p_{(A) D M}}=a+b f_{r}
$$

giving coefficients of $a=0.94(0.97)$ and $b=-0.04(+0.03)$ Myr for the VDM (VADM) bias.

The intensity biases found above are now applied to the PINT data in Figure 1. In an attempt to remove these biases VDM's are divided by 0.8 , an estimate of the bias found in Figure 8 ;, and VADM's are divided by 1.1 , an estimate of the bias found in Figure $8 \mathrm{~d}$. Vertical lines in Figure 10 connect the unbiased values (circles) with the values from Figure 1. The same inverse-distance squared smoothing applied in Figure 1 is then applied to the unbiased data in Figure 10 . This relatively minor biasing effect does not reveal any new long-term trends and no immediate signature of inner core nucleation is apparent.

Note that in this unbiasing effort we have used constant estimates of the dipole moment bias for all VDM's or VADM's, whereas a more accurate unbiasing would apply a dynamo regime specific correction that depends, for example, on reversal frequency according to (18). Although this approach will be difficult for Precambrian data where the reversal frequency record is discontinuous (e.g. Pavlov and Gallet, 2010; Biggin et al., 2011; Gallet et al., 2012), correlating polarity ratio with polarity reversal frequency may be a way to extend the record (e.g. Driscoll and Evans, 2016). More readily this bias could be applied to the paleointensity record over the last $180 \mathrm{Myr}$ where the reversal frequency is known, in order to test 
306

307

\section{CONCLUSIONS}

308 We have generated synthetic magnetic observations from numerical dynamos that span a range of dynamical 309

\section{CONFLICT OF INTEREST STATEMENT}

331 The authors declare that the research was conducted in the absence of any commercial or financial

\section{AUTHOR CONTRIBUTIONS}

333 The author conceived the project, analyzed the data, and wrote the article.

\section{FUNDING}

334 The author thanks the Carnegie Institution for Science for funding.

This is a provisional file, not the final typeset article 


\section{ACKNOWLEDGMENTS}

This article benefited from discussions with Chris Davies, Richard Bono, and Cian Wilson. Andrew Biggin (University of Liverpool) maintains the PINT database used here. Rayleigh (https://github.com/geodynamics/Rayleigh), the dynamo code used here, has been developed by Nicholas Featherstone (University of Colorado) with support by the National Science Foundation through the Computational Infrastructure for Geodynamics (CIG), and was supported by NSF grants NSF-0949446 and NSF-1550901. Carnegie's Memex high performance computational cluster was used to generate all numerical dynamos. The data can be made available upon request.

\section{REFERENCES}

Abrajevitch, A., Van der Voo, R., 2010. Incompatible Ediacaran paleomagnetic directions suggest an equatorial geomagnetic dipole hypothesis. Earth and Planetary Science Letters 293 (1), 164-170.

Acton, G. D., Petronotis, K. E., Cape, C. D., Ilg, S. R., Gordon, R. G., Bryan, P. C., 1996. A test of the geocentric axial dipole hypothesis from an analysis of the skewness of the central marine magnetic anomaly. Earth and Planetary Science Letters 144 (3), 337 - 346.

URL S0012821X96001689

Algeo, T. J., 1996. Geomagnetic polarity bias patterns through the Phanerozoic. Journal of Geophysical Research 101 (B2), 2785-2814.

Aubert, J., Gastine, T., Fournier, A., 2017. Spherical convective dynamos in the rapidly rotating asymptotic regime. Journal of Fluid Mechanics 813, 558-593.

Bazhenov, M. L., Levashova, N. M., Meert, J. G., Golovanova, I. V., Danukalov, K. N., Fedorova, N. M., 2016. Late Ediacaran magnetostratigraphy of Baltica: Evidence for Magnetic Field Hyperactivity? Earth and Planetary Science Letters 435, 124-135.

Biggin, A., Piispa, E., Pesonen, L., Holme, R., Paterson, G., Veikkolainen, T., Tauxe, L., 2015. Palaeomagnetic field intensity variations suggest Mesoproterozoic inner-core nucleation. Nature 526 (7572), 245-248.

Biggin, A., Strik, G., Langereis, C., 2009. The intensity of the geomagnetic field in the late-Archaean: new measurements and an analysis of the updated IAGA palaeointensity database. Earth, Planets, and Space $61(1), 9-22$.

Biggin, A. J., de Wit, M. J., Langereis, C. G., Zegers, T. E., Voûte, S., Dekkers, M. J., Drost, K., 2011. Palaeomagnetism of Archaean rocks of the Onverwacht Group, Barberton Greenstone Belt (southern Africa): Evidence for a stable and potentially reversing geomagnetic field at ca. $3.5 \mathrm{Ga}$. Earth and Planetary Science Letters 302 (3), 314-328.

Christensen, U., Holzwarth, V., Reiners, A., 2009. Energy flux determines magnetic field strength of planets and stars. Nature 457, 167-169.

Davies, C. J., 2015. Cooling history of Earths core with high thermal conductivity. Physics of the Earth and Planetary Interiors 247, 65-79.

Davies, C. J., Constable, C. G., 2014. Insights from geodynamo simulations into long-term geomagnetic field behaviour. Earth and Planetary Science Letters 404, 238-249.

Donadini, F., Pesonen, L. J., Korhonen, K., Deutsch, A., Harlan, S. S., 2011. Paleomagnetism and paleointensity of the $1.1 \mathrm{Ga}$ old diabase sheets from central Arizona. Geophysica 47 (1-2), 3-30.

Driscoll, P., Bercovici, D., 2014. On the thermal and magnetic histories of Earth and Venus: Influences of melting, radioactivity, and conductivity. Physics of the Earth and Planetary Interiors 236, 36-51. 
376

Driscoll, P., Olson, P., 2009. Effects of buoyancy and rotation on the polarity reversal frequency of gravitationally driven numerical dynamos. Geophys. J. Int. 178 (3), 1337-1350, doi: 10.1111/j.1365246X.2009.04234.x.

Driscoll, P., Olson, P., 2011. Superchron cycles driven by variable core heat flow. Geophysical Research Letters 38 (9), L09304.

Driscoll, P. E., 2016. Simulating 2 Ga of geodynamo history. Geophysical Research Letters 43 (11), 5680-5687.

Driscoll, P. E., Evans, D. A., 2016. Frequency of Proterozoic geomagnetic superchrons. Earth and Planetary Science Letters 437, 9 - 14.

Evans, D. A., Li, Z., Kirschvink, J. L., Wingate, M. T., 2000. A high-quality mid-Neoproterozoic paleomagnetic pole from South China, with implications for ice ages and the breakup configuration of Rodinia. Precambrian Research 100 (1), 313-334.

Evans, D. A. D., 11 2006. Proterozoic low orbital obliquity and axial-dipolar geomagnetic field from evaporite palaeolatitudes. Nature 444, 51-55.

URL http://dx.doi.org/10.1038/nature05203

Featherstone, N. A., Hindman, B. W., 2016. The spectral amplitude of stellar convection and its scaling in the high-Rayleigh-number regime. The Astrophysical Journal 818 (1), 32.

Gallet, Y., Pavlov, V., Halverson, G., Hulot, G., 2012. Toward constraining the long-term reversing behavior of the geodynamo: A new Maya superchron 1 billion years ago from the magnetostratigraphy of the Kartochka Formation (southwestern Siberia). Earth and Planetary Science Letters 339, 117-126.

Gubbins, D., Zhang, K., 1993. Symmetry properties of the dynamo equations for paleomagnetism and geomagnetism. Phys. Earth Planet. Inter. 75, 225-241.

Halls, H. C., Lovette, A., Hamilton, M., Söderlund, U., 2015. A paleomagnetic and U-Pb geochronology study of the western end of the Grenville dyke swarm: Rapid changes in paleomagnetic field direction at ca. 585 Ma related to polarity reversals? Precambrian Research 257, 137-166.

Johnson, C., McFadden, P., 2015. 5.11 - The Time-Averaged Field and Paleosecular Variation. In: Schubert, G. (Ed.), Treatise on Geophysics (Second Edition), second edition Edition. Elsevier, Oxford, pp. 385 417.

Johnson, H. P., Van Patten, D., Tivey, M., Sager, W. W., 1995. Geomagnetic polarity reversal rate for the Phanerozoic. Geophysical Research Letters 22 (3), 231-234.

Kent, D. V., Smethurst, M. A., 1998. Shallow bias of paleomagnetic inclinations in the Paleozoic and Precambrian. Earth and Planetary Science Letters 160 (3-4), 391-402.

Klein, R., Salminen, J., Mertanen, S., 2015. Baltica during the Ediacaran and Cambrian: A paleomagnetic study of Hailuoto sediments in Finland. Precambrian Research 267, 94-105.

Landeau, M., Aubert, J., Olson, P., 2017. The signature of inner-core nucleation on the geodynamo. Earth and Planetary Science Letters 465, 193-204.

Levashova, N. M., Bazhenov, M. L., Meert, J. G., Danukalov, K. N., Golovanova, I. V., Kuznetsov, N. B., Fedorova, N. M., 2015. Paleomagnetism of upper Ediacaran clastics from the South Urals: Implications to paleogeography of Baltica and the opening of the Iapetus Ocean. Gondwana Research 28 (1), 191 208.

Lhuillier, F., Gilder, S. A., 2013. Quantifying paleosecular variation: insights from numerical dynamo simulations. Earth and Planetary Science Letters 382, 87-97.

Macouin, M., Valet, J., Besse, J., Buchan, K., Ernst, R., LeGoff, M., Scharer, U., 2003. Low paleointensities recorded in 1 to 2.4 Ga Proterozoic dykes, Superior Province, Canada. Earth and Planetary Science Letters 213 (1), 79-95. 
Maloof, A. C., Halverson, G. P., Kirschvink, J. L., Schrag, D. P., Weiss, B. P., Hoffman, P. F., 2006. Combined paleomagnetic, isotopic, and stratigraphic evidence for true polar wander from the Neoproterozoic Akademikerbreen Group, Svalbard, Norway. Geological Society of America Bulletin 118 (9-10), 1099-1124.

Matsui, H., Heien, E., Aubert, J., Aurnou, J. M., Avery, M., Brown, B., Buffett, B. A., Busse, F., Christensen, U. R., Davies, C. J., et al., 2016. Performance benchmarks for a next generation numerical dynamo model. Geochemistry, Geophysics, Geosystems 17 (5), 1586-1607.

McCausland, P. J., Hankard, F., der Voo, R. V., Hall, C. M., 2011. Ediacaran paleogeography of Laurentia: Paleomagnetism and 40Ar-39Ar geochronology of the 583Ma Baie des Moutons syenite, Quebec. Precambrian Research 187 (1), 58 - 78.

McElhinny, M., 2004. Geocentric Axial Dipole Hypothesis: A Least Squares Perspective. Vol. Timescales of the Paleomagnetic Field of Geophysical Monograph Series. American Geophysical Union, Washington, D. C., pp. 1-12.

McMillan, D., Constable, C., Parker, R., Glatzmaier, G., 2001. A statistical analysis of magnetic fields from some geodynamo simulations. Geochem. Geophys. Geosyst 2.

Meert, J. G., Tamrat, E., Spearman, J., 2003. Non-dipole fields and inclination bias: insights from a random walk analysis. Earth and Planetary Science Letters 214 (3-4), 395-408.

Merrill, R., McElhinny, M., McFadden, P., 1996. The magnetic field of the Earth: Paleomagnetism, the core, and the deep mantle. Academic Press, New York.

Merrill, R. T., McFadden, P. L., 2003. The geomagnetic axial dipole field assumption. Physics of the Earth and Planetary Interiors 139 (3), $171-185$.

Nimmo, F., 2015. 8.02 - Energetics of the Core. In: Schubert, G. (Ed.), Treatise on Geophysics (Second Edition), second edition Edition. Elsevier, Oxford, pp. 27 - 55.

Panzik, J., Evans, D., 2014. Assessing the GAD hypothesis with paleomagnetic data from large Proterozoic dike swarms. Earth and Planetary Science Letters 406, 134-141.

Pavlov, V., Gallet, Y., 2010. Variations in geomagnetic reversal frequency during the Earth's middle age. Geochemistry, Geophysics, Geosystems 11 (1).

Pesonen, L. J., Halls, H. C., 1983. Geomagnetic field intensity and reversal asymmetry in late Precambrian Keweenawan rocks. Geophysical Journal International 73 (1), 241-270.

Raub, T., Kirschvink, J., Evans, D., 2015. 5.14 - True Polar Wander: Linking Deep and Shallow Geodynamics to Hydro- and Biospheric Hypotheses. In: Schubert, G. (Ed.), Treatise on Geophysics (Second Edition), second edition Edition. Elsevier, Oxford, pp. 511 - 530.

Smirnov, A. V., Tarduno, J. A., Kulakov, E. V., McEnroe, S. A., Bono, R. K., 2016. Paleointensity, core thermal conductivity and the unknown age of the inner core. Geophysical Journal International, ggw080.

Sprain, C. J., Feinberg, J. M., Geissman, J. W., Strauss, B., Brown, M. C., 2016. Paleointensity during periods of rapid reversal: A case study from the Middle Jurassic Shamrock batholith, western Nevada. Bulletin 128 (1-2), 223-238.

Swanson-Hysell, N. L., Maloof, A. C., Kirschvink, J. L., Evans, D. A., Halverson, G. P., Hurtgen, M. T., 2012. Constraints on Neoproterozoic paleogeography and Paleozoic orogenesis from paleomagnetic records of the Bitter Springs Formation, Amadeus Basin, central Australia. American Journal of Science 312 (8), 817-884.

Swanson-Hysell, N. L., Maloof, A. C., Weiss, B. P., Evans, D. A., 2009. No asymmetry in geomagnetic reversals recorded by 1.1-billion-year-old Keweenawan basalts. Nature Geoscience 2 (10), 713.

Tauxe, L., Yamazaki, T., 2015. 5.13 - Paleointensities. In: Schubert, G. (Ed.), Treatise on Geophysics (Second Edition), second edition Edition. Elsevier, Oxford, pp. 461 - 509. 


\begin{tabular}{r|r|r|r|r|r|r|r|r}
$d T / d r_{i}$ & $K E$ & $M E$ & $\mathrm{kyr}$ & $N_{\text {eq }}$ & $N_{\text {rev }}$ & $\tau_{\text {crit }}$ & $V D M / D M$ & $V A D M / A D M$ \\
\hline 0.8 & 86 & 944 & 5185 & 0 & 0 & 30 & 0.95 & 0.99 \\
1.0 & 116 & 1080 & 6039 & 0 & 0 & 20 & 0.94 & 0.98 \\
2.0 & 327 & 887 & 9702 & 0 & 0 & 20 & 0.93 & 0.99 \\
3.0 & 656 & 418 & 5990 & 27 & 7 & 30 & 0.90 & 0.99 \\
4.0 & 893 & 442 & 7650 & 229 & 20 & 30 & 0.81 & 1.03 \\
5.0 & 1110 & 549 & 5686 & 310 & 30 & 30 & 0.72 & 1.08 \\
6.0 & 1300 & 717 & 4852 & 319 & 33 & 30 & 0.68 & 1.13 \\
7.0 & 1490 & 889 & 4157 & 373 & 33 & 30 & 0.63 & 1.18 \\
8.0 & 1690 & 1020 & 3976 & 400 & 28 & 30 & 0.60 & 1.20 \\
9.0 & 1880 & 1190 & 3517 & 432 & 27 & 30 & 0.59 & 1.21 \\
10.0 & 2050 & 1370 & 4277 & 349 & 33 & 40 & 0.60 & 1.20 \\
12.0 & 2430 & 1650 & 3903 & 470 & 32 & 20 & 0.55 & 1.21
\end{tabular}

Table 1. Dynamo model properties: bottom boundary heat flux $d T / d r_{i}$, kinetic energy (KE), magnetic energy (ME), length of run in kyr, number of dipole equator crossings $N_{e q}$, number of polarity reversals $N_{\text {rev }}$, critical running average length $\tau_{\text {crit }}$ when $\alpha_{95}<10^{\circ}$, ratio of observed to true virtual dipole moments, and the same ratio of axial dipole moments.

Thomas, D. N., Piper, J. D. A., 1995. Evidence for the existence of a transitional geomagnetic field recorded in a Proterozoic lava succession. Geophysical Journal International 122 (1), 266-282.

Thomas, N., 1993. An integrated rock magnetic approach to the selection or rejection of ancient basalt samples for palaeointensity experiments. Physics of the Earth and Planetary Interiors 75 (4), 329 - 342.

Torsvik, T. H., Van der Voo, R., Preeden, U., Mac Niocaill, C., Steinberger, B., Doubrovine, P. V., van Hinsbergen, D. J., Domeier, M., Gaina, C., Tohver, E., et al., 2012. Phanerozoic polar wander, palaeogeography and dynamics. Earth-Science Reviews 114, 325-368.

Valet, J., 2003. Time variations in geomagnetic intensity. Rev. Geophys 41 (1), 1004.

Van der Voo, R., 1990. The reliability of paleomagnetic data. Tectonophysics 184 (1), 1-9.

Veikkolainen, T., Heimpel, M., Evans, M. E., Pesonen, L. J., Korhonen, K., 2017. A paleointensity test of the geocentric axial dipole (GAD) hypothesis. Physics of the Earth and Planetary Interiors 265, 54-61.

Veikkolainen, T., Pesonen, L., Korhonen, K., 2014. An analysis of geomagnetic field reversals supports the validity of the Geocentric Axial Dipole (GAD) hypothesis in the Precambrian. Precambrian Research 244, 33-41.

Wicht, J., 2005. Palaeomagnetic interpretation of dynamo simulations. Geophys. J. Int. 162 (2), 371-380.

Williams, G. E., Schmidt, P. W., 2004. Neoproterozoic glaciation: reconciling low paleolatitudes and the geologic record. The Extreme Proterozoic: Geology, Geochemistry, and Climate, 145-159.

Yu, Y., Dunlop, D. J., 2001. Paleointensity determination on the late precambrian Tudor Gabbro, Ontario. Journal of Geophysical Research: Solid Earth 106 (B11), 26331-26343. 


\section{FIGURE CAPTIONS}
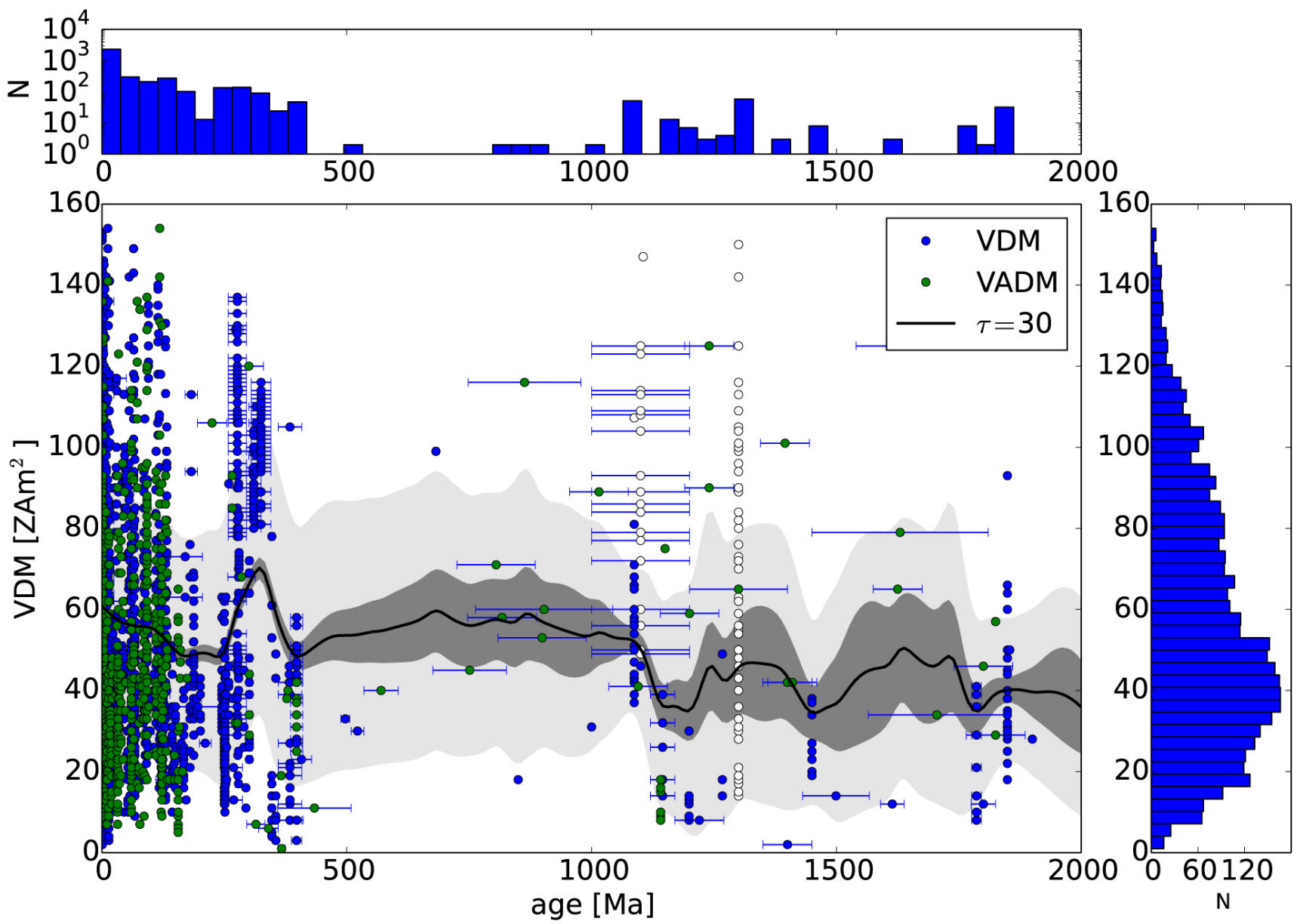

Figure 1. Paleointensity (VDM and VADM) from the PINT database (dots) with inverse-distance squared smoothing (solid line) applied to filled circles. Open circles are from paleointensity studies that either contain directional anomalies (Pesonen and Halls, 1983) or low temperature components (Thomas, 1993; Thomas and Piper, 1995). Panel right: histogram of VDM and VADM. Panel top: histogram of ages. 

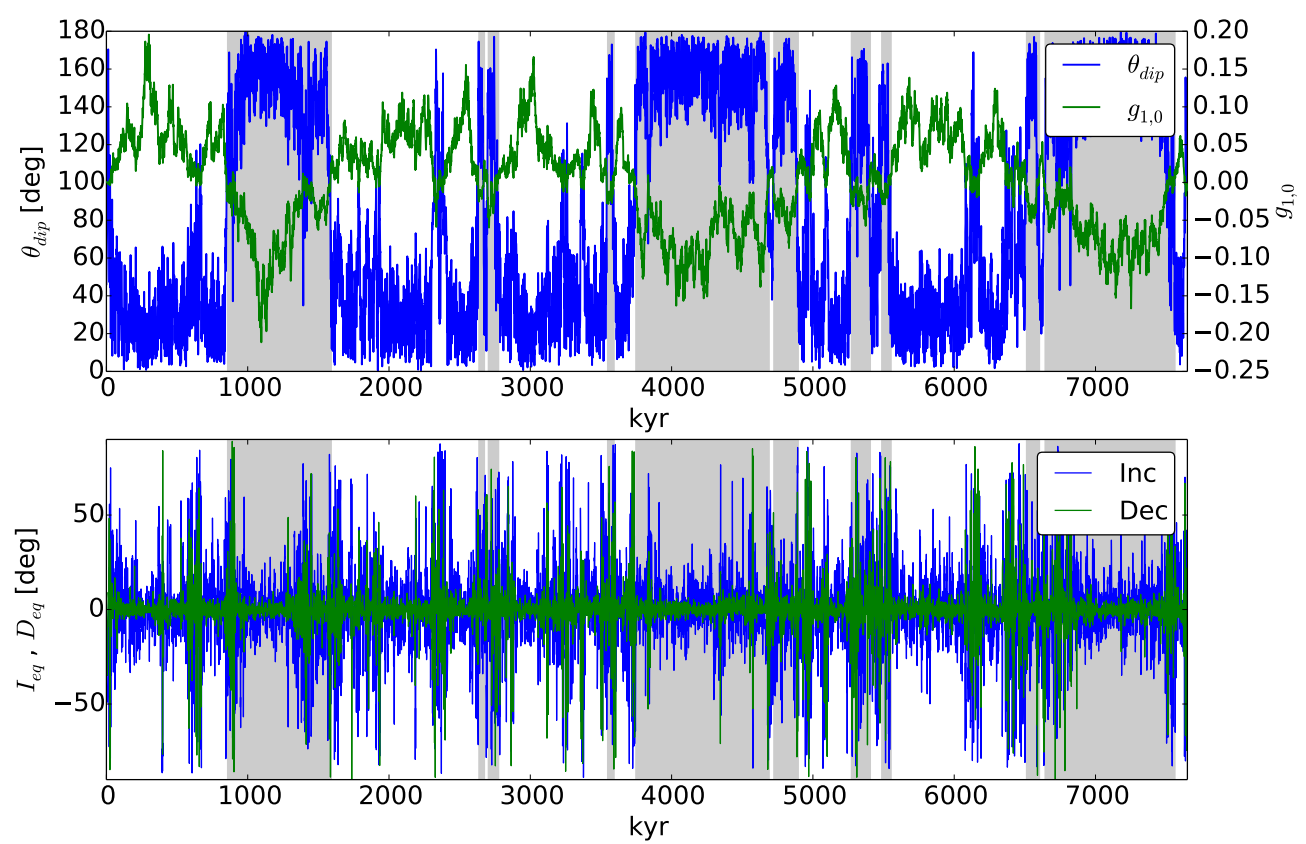

Figure 2. Time series of model $4\left(d T / d r_{b}=4\right)$ : a) dipole co-latitude $\theta_{\text {dip }}$ (left axis) and $g_{1,0}$ Gauss coefficient (right axis). Background shading denotes polarity chrons. b) Magnetic inclination $I_{e q}$ and declination $D_{e q}$ of synthetic observations at equator $(\theta=\pi / 2, \phi=0)$.
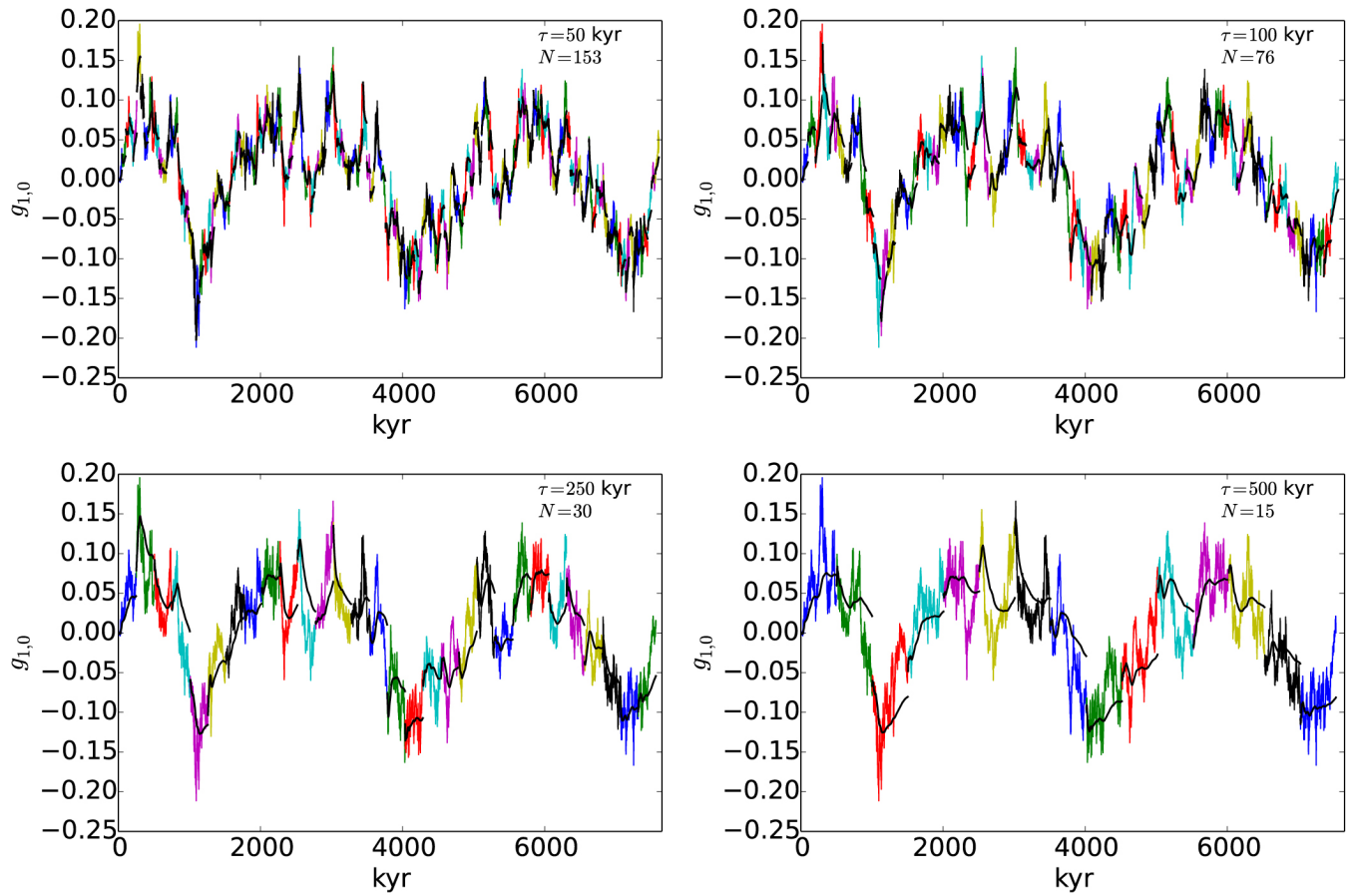

Figure 3. Smoothing (black) of subsets (colors) of $g_{1,0}$ time series from model 4. a) Smoothing length of $\tau=50$ kyr. b) $\tau=100$ kyr. c) $\tau=250$ kyr. d) $\tau=500$ kyr. 

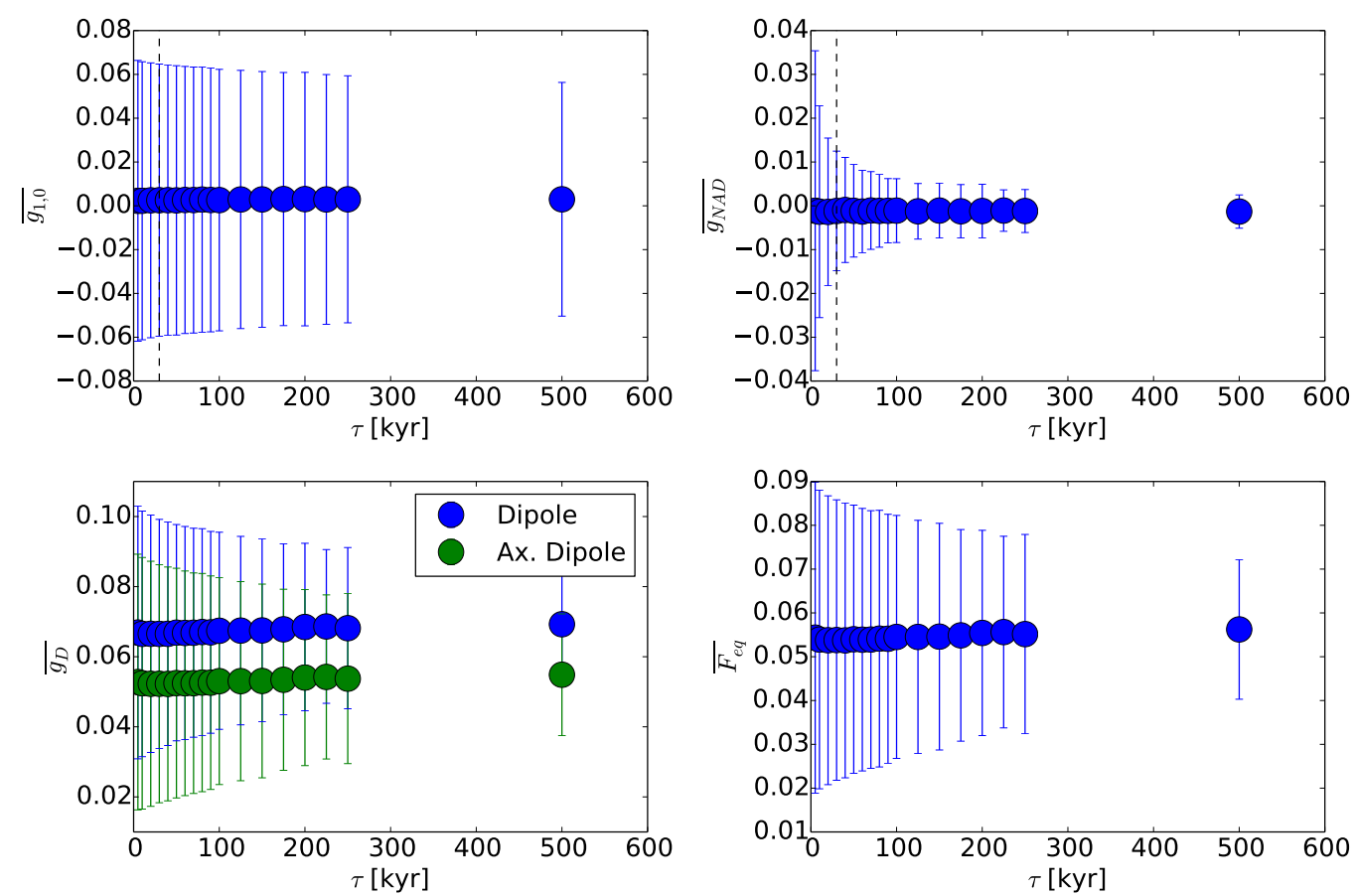

Figure 4. From model 4, mean and standard deviation (error bars) of running means of dynamo statistics for a range of smoothing lengths $\tau$. a) $\overline{g_{1,0}}$. b) Gauss coefficients of non-axial dipole $\overline{g_{N A D}}$ from (1). c) Dipole $\overline{g_{D}}$ from (2). d) Magnetic amplitude $\overline{F_{e q}}$ at a point on the equator from (5). 

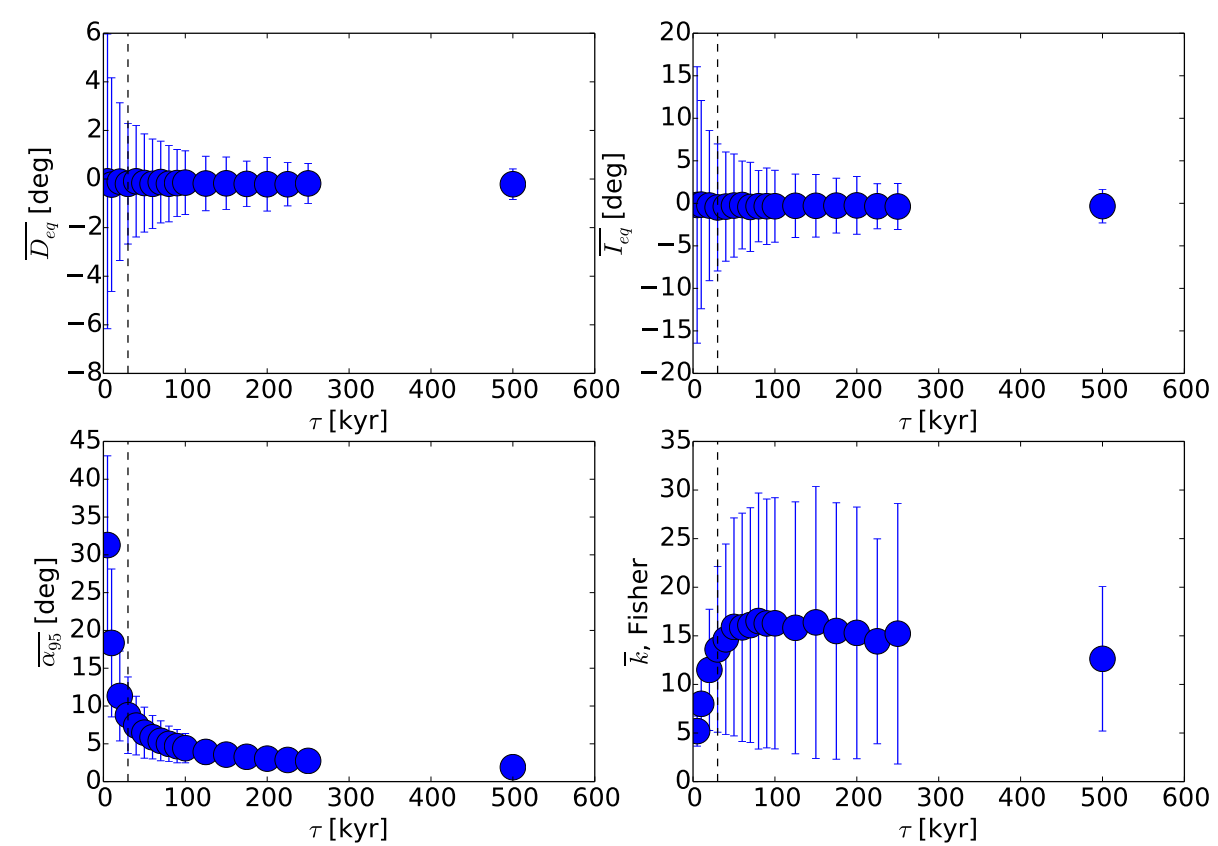

Figure 5. From model 4, mean and standard deviation (error bars) of running means of synthetic observations at the equator for a range of smoothing lengths $\tau$. a) Magnetic declination $\overline{D_{e q}}$ from (6). b) Magnetic inclination $\overline{I_{e q}}$ from (7). c) Angular spread of magnetic pole location at $95 \%$ confidence level, $\overline{\alpha_{95}}$ from (8). d) Fisher's precision parameter $\bar{k}$ from $(9)$. 

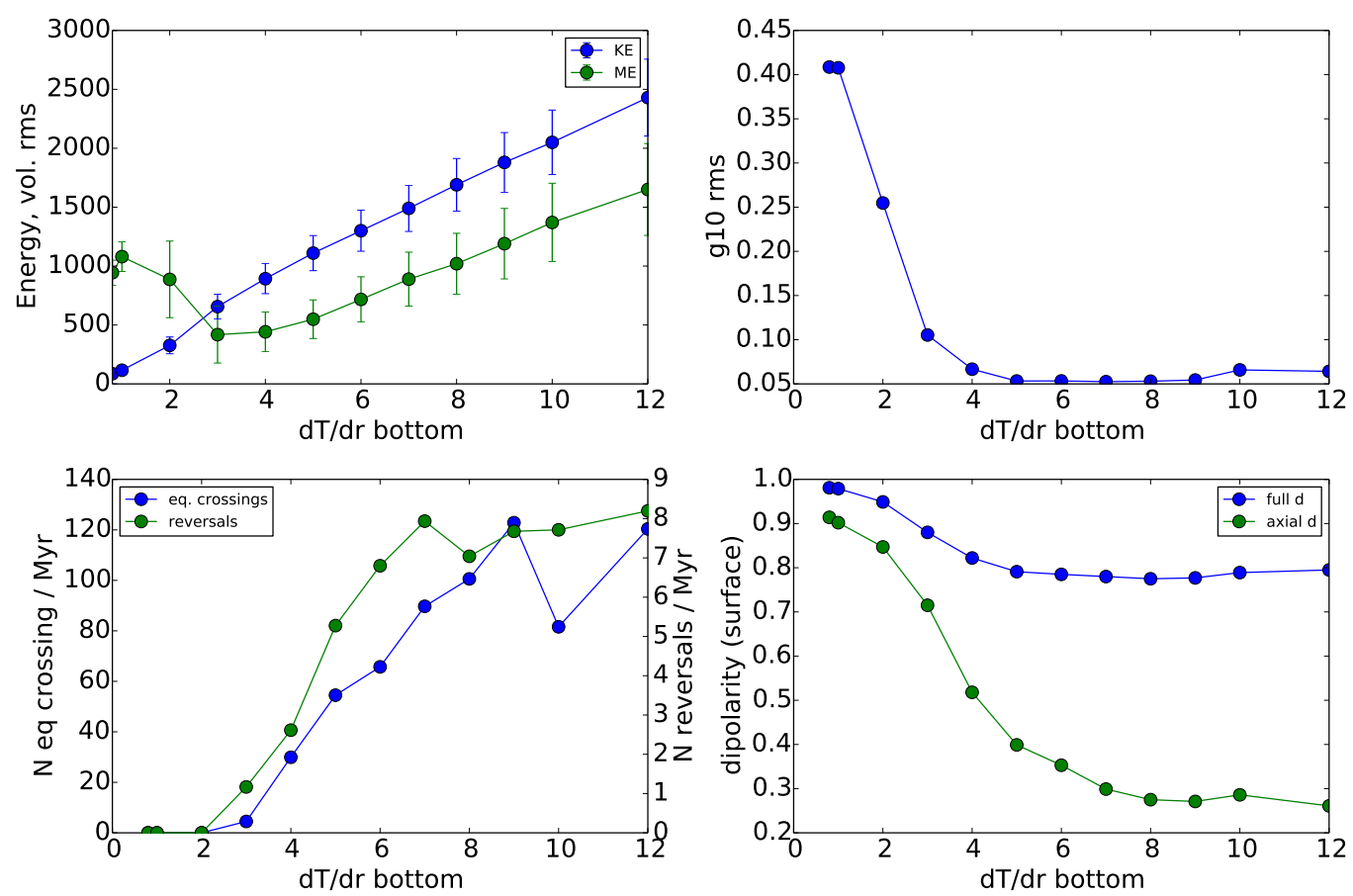

Figure 6. Comparison of time average dynamo statistics. a) Time averaged volumetric rms kinetic (KE) and magnetic energies (ME). b) Time averaged Gauss coefficient $g_{1,0}$. c) Number of dipole axis equator crossings (left scale) and number of reversals (right scale) per Myr. d) Time averaged dipolarity of Gauss coefficients for the full dipole $g_{D} / g_{r m s}$ and the axial dipole $g_{1,0} / g_{r m s}$.
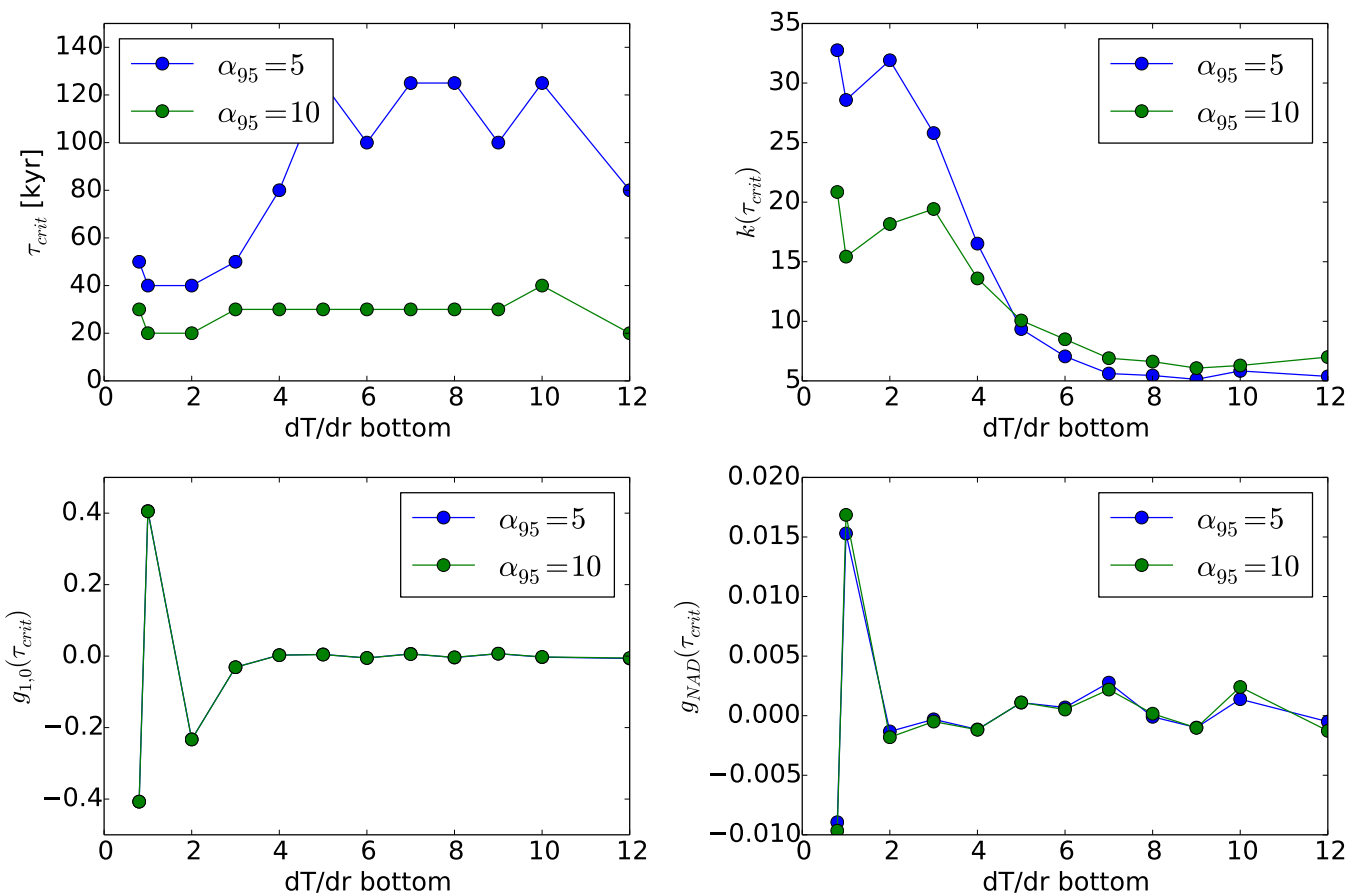

Figure 7. a) Comparison of critical running average length $\tau_{\text {crit }}$ where $\alpha_{95, \text { crit }}<5^{\circ}$ or $10^{\circ}$ for all models. b) Same for Fisher's $k$ parameter. c) Same for $g_{1,0}$. d) Same for $g_{N A D}$. 

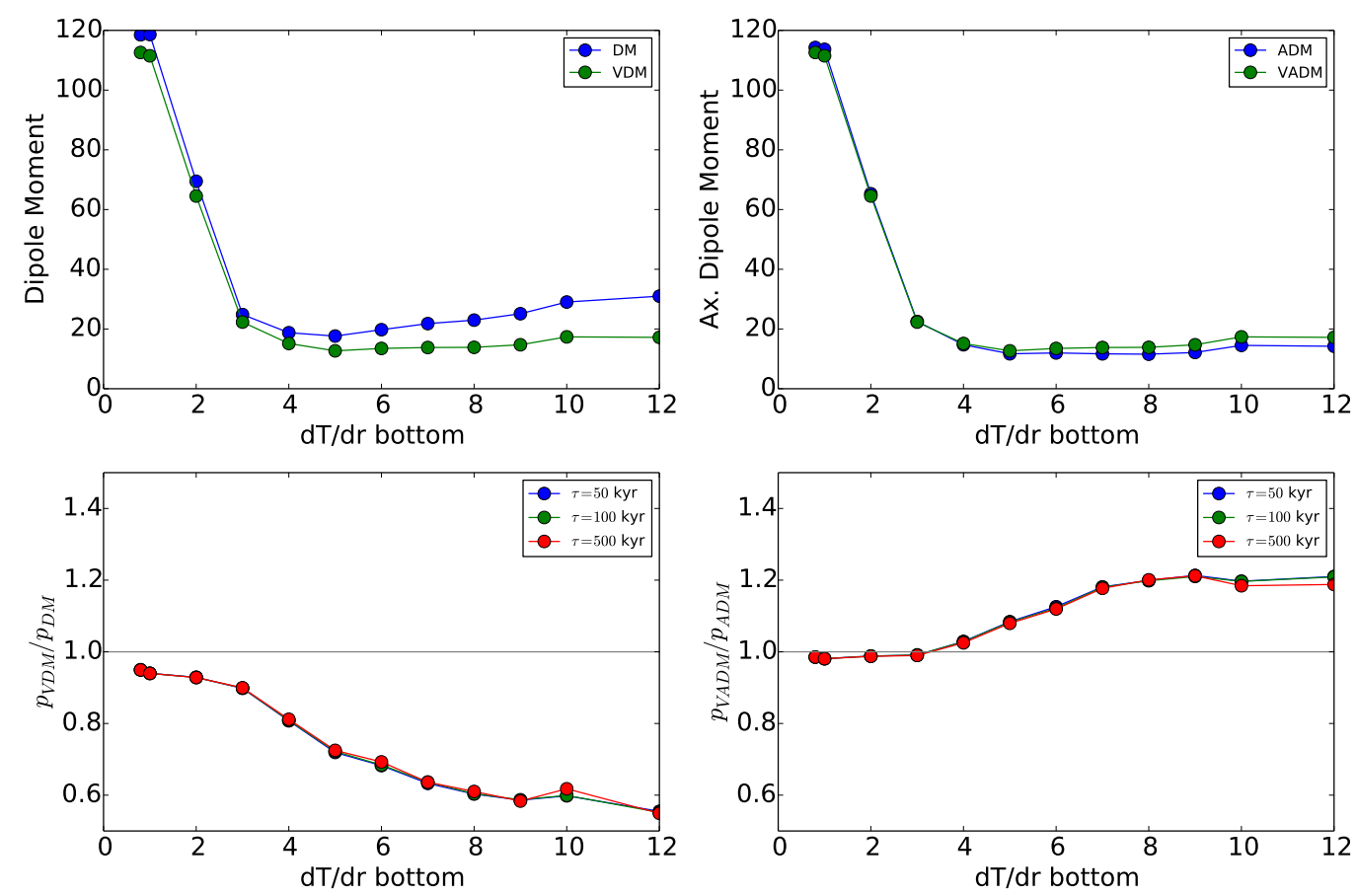

Figure 8. Comparison of synthetic observations made at the equator for all models, with $\tau=50$ kyr. a) True dipole moment $p_{D M}$ from (11) and "observed" $p_{V D M}$ from (12). b) True axial dipole moment $p_{A D M}$ and "observed" $p_{V A D M}$ from (13). c) Ratio of $p_{V D M} / p_{D M}$ from (a). d) Ratio of $p_{V A D M} / p_{A D M}$ from (b).
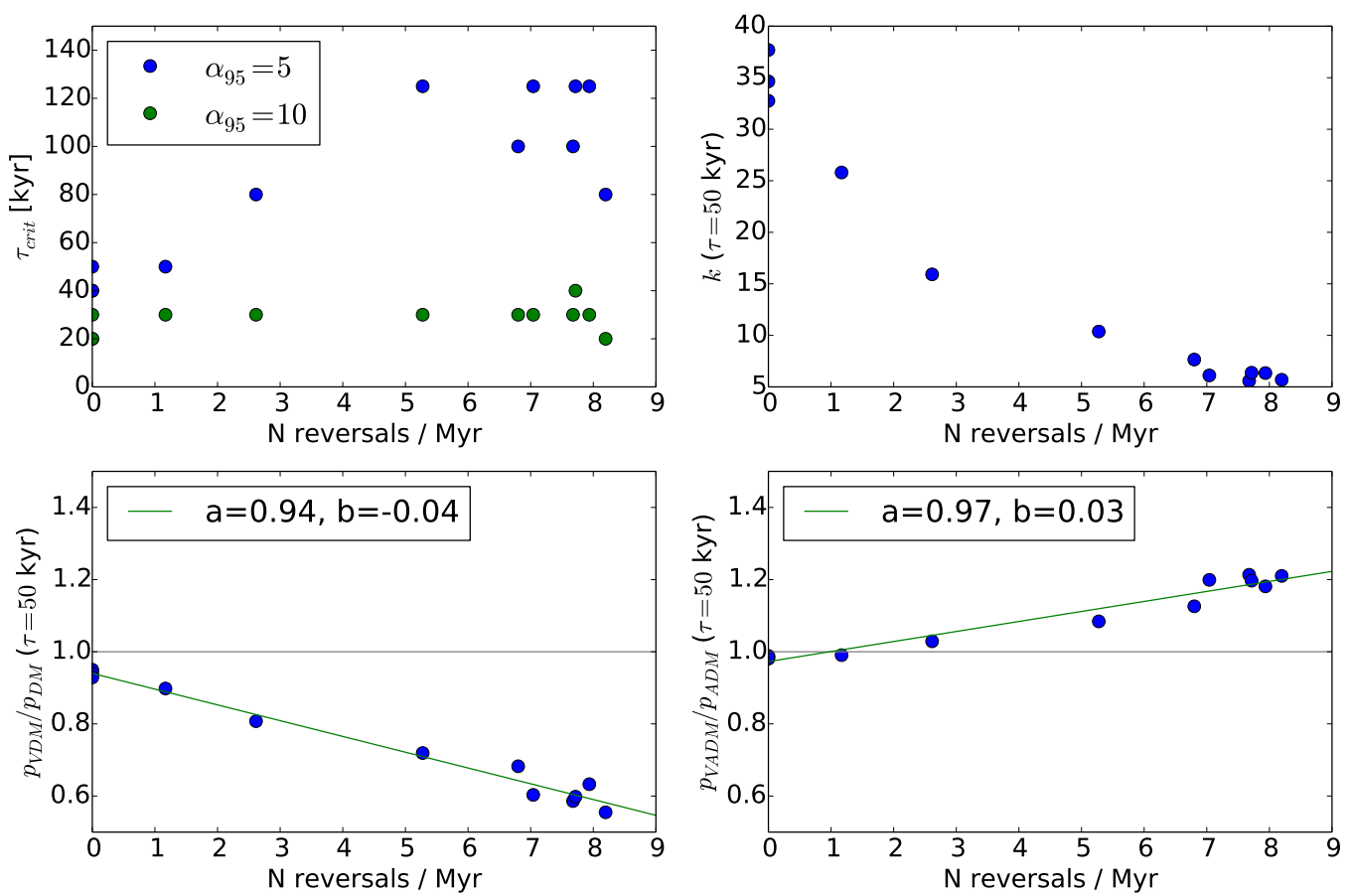

Figure 9. Dynamo model properties as a function of reversal rate per Myr, $f_{r}$. a) Critical averaging time $\tau_{\text {crit }}$ to achieve $\alpha_{95}<5^{\circ}$ (blue) and $<10^{\circ}$ (red). b) Fisher $k$ statistic at $\tau=50$ kyr. c) Ratio of $p_{V D M} / p_{D M}$ with linear fit: $p_{V D M} / p_{D M}=a+b f_{r}$, where $f_{r}$ is reversal frequency per Myr and coefficients are shown in the legend. d) Same as (c) but for $p_{V A D M} / p_{A D M}$. 


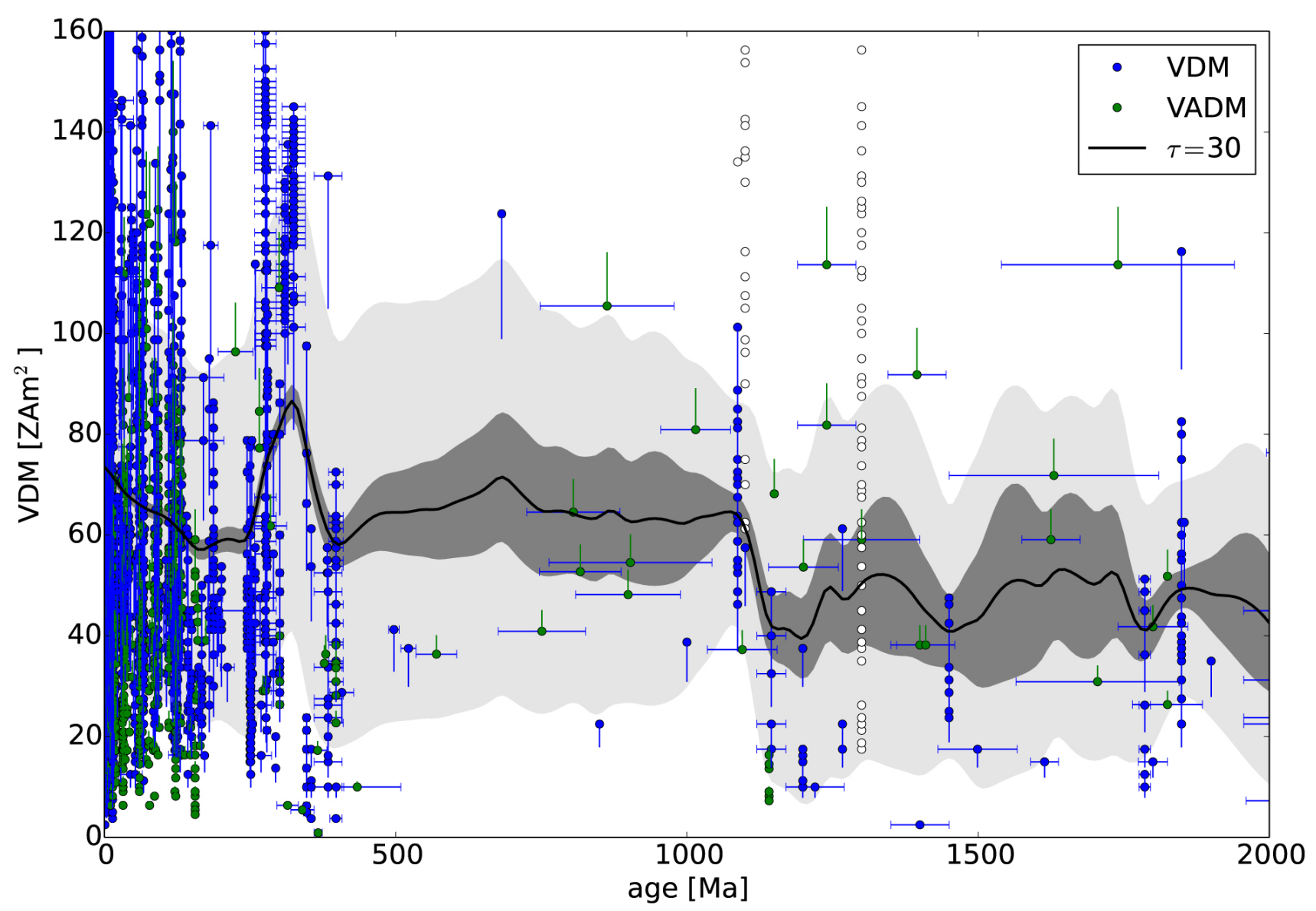

Figure 10. Unbiased paleointensity (VDM and VADM) from the PINT database with inverse-distance squared smoothing (solid line) applied to filled circles. VDM's are divided by 0.8 , an estimate of the bias found in Figure 8c, and VADM's are divided by 1.1, an estimate of the bias found in Figure 8d. Vertical lines connect biased to unbiased values. 